\title{
Monitoring of Tourist Territory Sustainable Development on Regional Level
}

\author{
Evgeniya Atamas*, and Danil Kotelnikov \\ Kuban State University, Stavropolskaya Str., 149, 350040 Krasnodar, Russia
}

\begin{abstract}
This paper states the study of approaches to the formation of monitoring metrics for tourist territory sustainable development. It is noted that the statistical framework for monitoring of tourist territory sustainable development will allow to timely react on the emerging disbalance and achieve positive results in the tourist territory sustainable development management. It is concluded that for the effective organization of the system for monitoring of tourist territory sustainable development, it is required to make enterprises responsible for the provision of statistical reporting in special fillable forms that shall include indices required for the monitoring. In order to organize the monitoring is presented the model for monitoring tourist territory sustainable development data store formation.
\end{abstract}

\section{Introduction}

The tourist territory sustainable development management is related to the required formation of information field for preparation of solutions in the sphere of the tourist development planning taking into account the compliance with the "sustainable development" concept. It is known that tourism has a material effect on the development of host territories, provided that such an effect could be direct and indirect.

The direct tourism effect is reflected on the macroeconomic development indices, parameters of social sphere status, environment, native population living standards and relationships with visitors. The indirect tourism effect or the multiplier effect is connected with the special interindustry and social and economic character of tourism, as according to the Word Tourism Organization (UNWTO) standards, the tourism is not a separate economic sector, but rather combines the interrelated activities: collective accommodation facilities, passenger transport, public catering, entertainment industry, etc.

Considering the vast number of impact factors and multiple parties involved, the regional tourist territory sustainable development management becomes topical. The prerequisite of such management is the provision of regional tourist territory sustainable development.

* Corresponding author: eatamas@bk.ru 


\section{Methods and Approaches to Tourist Territory Sustainable Development Assessment}

The key element of tourism as the system is a territory attracting tourists, where they travel and spend a certain time in order to rest, recreation and gain new experiences.

The tourism is highly responsive to political instability and environmental catastrophes, exposed to market fluctuations of countries where tourists arrive.

Meanwhile it should be noted that existing studies are short of the common position in understanding what the tourist territory is, its parameters, including administrative and geographical boundaries, its place in the systems of tourist and recreation zoning, administrative and territorial structure, criteria for categorization the territory as tourist.

The sustainable development concept that initially emerged as the response to global challenges and threat to the global community; and recently is taken more specific spatial form spreading to the national, regional and local levels [1].

In such circumstances the sustainable development of territories of tourist and recreation specialization becomes the important condition of the support of sustainable development on the regional level.

For the first time the sustainable development issue was underlined in the Agenda 21 [2], further development specialists and scientists attempted to develop main indices characterizing the tourism possibilities from the point of income generation and evaluation of adverse effects.

Apart from the global role, the monitoring enables the detection and timely reaction to challenges arising on the regional and local level.

One of the key issues is the determination of tourist flow. The tourist flow scope and structural features are the most important indices characterizing the tourism industry development on the regional and local level. Moreover, the tourist flow dynamics "is one of the key performance indicators of national policy in the sphere of tourism, provides guides for the development of strategy and tactics of tourist market participants" [3]. Researchers D.V. Maksimov and A.I. Estafiev noted that "the tourist flow is characterized by the physical volume of tourist activities expressed not only by the number of vacationers visited the territory, but the number of stayed nights, actual visitors, arrivals, etc.; the spatial differentiation and tourist activity dynamics" [4]. After major studies conducted in the Krasnodar territory, researchers have developed the method for tourist flow scope determination on the basis of data on mobile user (roamer) movement arriving to the territory of tourist region and using activated SIM-cards of home region.

It shall be noted that separate constituent territories of the Russian Federation make attempts to register flashpackers. For example, in the Krasnodar territory random households are polled in order to determine the number of flashpackers.

As rightly been said by some researchers 'the registration of visitors' number in certain city or region is the most challenging issue in the tourism statistics methodology, especially in Russia" [5].

In addition, the developed 2008 International Recommendations for Tourism Statistics allow to analyse the regional activities in sphere of tourism organisation. Such recommendations are focused on the provision of general reference information to be used in tourism statistics generation to countries [6].

The unsolved part of general methodological issue of tourist flow registration in Russia is the determination of such visitor categories that are subject to be registered within the official statistical measurement as members of tourist flow. Thus, in accordance of the Federal Law "On the Fundamental Principles of Tourist Activities" [7], to tourists are referred persons who visit places of temporary stay and stay there for minimum one night and have objectives not related to the profit generation in the host territory. 
Material difficulties attribute to the registration of informal vacationer sector. The solution if this issue within the Federal State Statistic Measurement currently is impossible, because such measurement foresees "the obtaining of information on only collective accommodation facilities activities: their number, room capacity, number of accommodated persons, revenues, etc.".

\section{Development of Tourist Territory Sustainable Development Model}

Manifested changes of indices in the mentioned spheres shall be included into the tourist territory sustainable development monitoring. The selection of such indices is determined by the content of processes proceeding under the influence of internal tourist flow (picture 1).

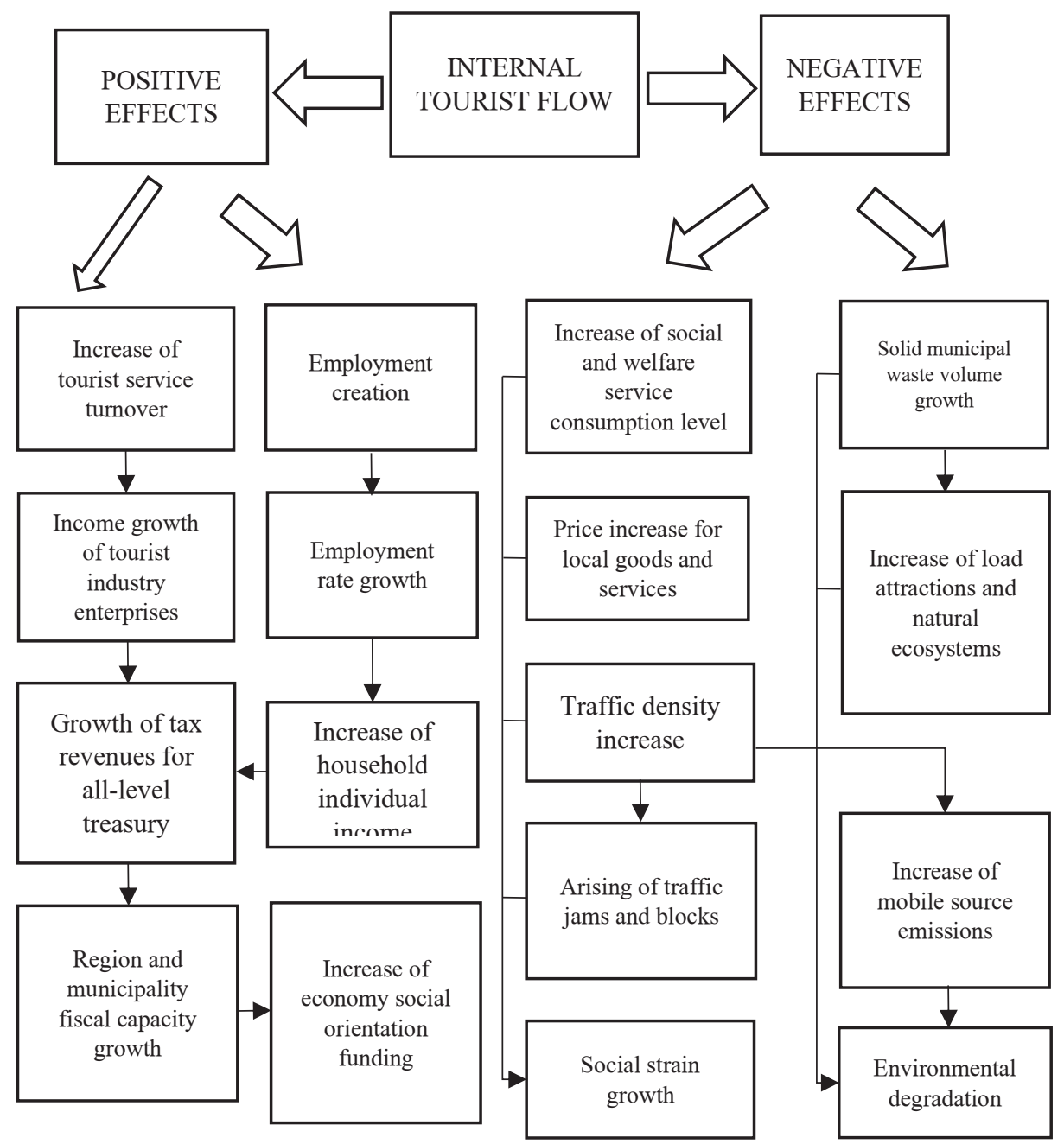

Fig. 1. Positive and negative effects of tourist flow impact on regional tourist territories (Drafted by the author)

Changes that are available in the natural and cultural environment are significant for the region development, for this reason our action shall not be ignored by the decision-makers. 
Apart from observed tourism positive effects: work places, economic activity, social service quality improvement, we can also separate negative results: environmental damage, problems with local population; all this reflects the region or enterprises income. For example, V.V. Gassiy has considered issues of the Russian industrialization that was accompanied by environmental and economic conflicts. Such conflicts were results of the implementation of natural resources utilization investment projects [8].

The level of tourism impact on the region can characterize also the region stability level from the point of social and economic parameters [9].

Such parameters are focused on both tourism impact and sustainability and more conventional management parameters that correspond certain needs of the separate region. Based on the suggested mechanisms of selection and formation of tourist territory assessment indicators, we offer the following parameters $[10 ; 11]$. They allow to form the data store for tourist territory sustainable development monitoring in our country (Table 1).

Table 1. Set of main recommended parameters for regional tourist territory sustainable development monitoring (drafted by the author).

\begin{tabular}{|c|c|}
\hline $\begin{array}{l}\text { Parameter } \\
\text { group name }\end{array}$ & Parameter name \\
\hline Economic & $\begin{array}{l}\text { - Alternative agriculture income, revenues from the agritourism; } \\
\text { - Amount of direct and indirect expenses for tourism development from local } \\
\text { budgets; } \\
\text { - Direct and indirect expenses for tourism development from external } \\
\text { sources; } \\
\text { - Business share owned by strangers in relation to tourist territory } \\
\text { companies; } \\
\text { - Local prices to average country prices ratio; } \\
\text { - Number of units carrying out retail trade of local products. }\end{array}$ \\
\hline Social & $\begin{array}{l}\text { - Amount of expenses on social-oriented economic sectors' funding; } \\
\text { - Local population life quality satisfaction level; } \\
\text { - Tourist satisfaction from tourist product quality; } \\
\text { - Relation of local citizens to tourists (euphoria, apathy, irritation, } \\
\text { antagonism); } \\
\text { - Share of tourist industry enterprises providing services annually; } \\
\text { - Number of events/festivals focused on local culture }\end{array}$ \\
\hline Environmental & $\begin{array}{l}\text { - Number of projects connected with renewable energy; } \\
\text { - Share of tourist territory land plots affected by negative tourist flow effects; } \\
\text { - Share of tourist territory land plots used for sustainable tourism; } \\
\text { - Share of solid municipal wastes collected for treatment; } \\
\text { - Territory usage density; } \\
\text { - Number of threatened and endangered species; } \\
\text { - Number of protected natural area visitors }\end{array}$ \\
\hline
\end{tabular}

In order to form the data store, the reporting parameters shall comply with the following obligatory criteria: 1) accessibility; 2) population of analysis coverage; 3) validity and credibility; 4) timeliness; 5) consistency and uniformity. The achievement of the mentioned criteria is practical on the ground of obtaining reporting from statistical measurement objects, that in such case appeared to be such interested parties as enterprises, local communities and tourists. In order to obtain the required information, it is offered to make enterprises responsible for the provision of statistical reporting in special fillable forms that shall include indices required for the monitoring.

If the index specifics require the absence of reasonable possibility to obtain data on such index using documentary reporting, the statistical measurement can be arranged in the form of local population and tourist flow members poll (Figure 2). 


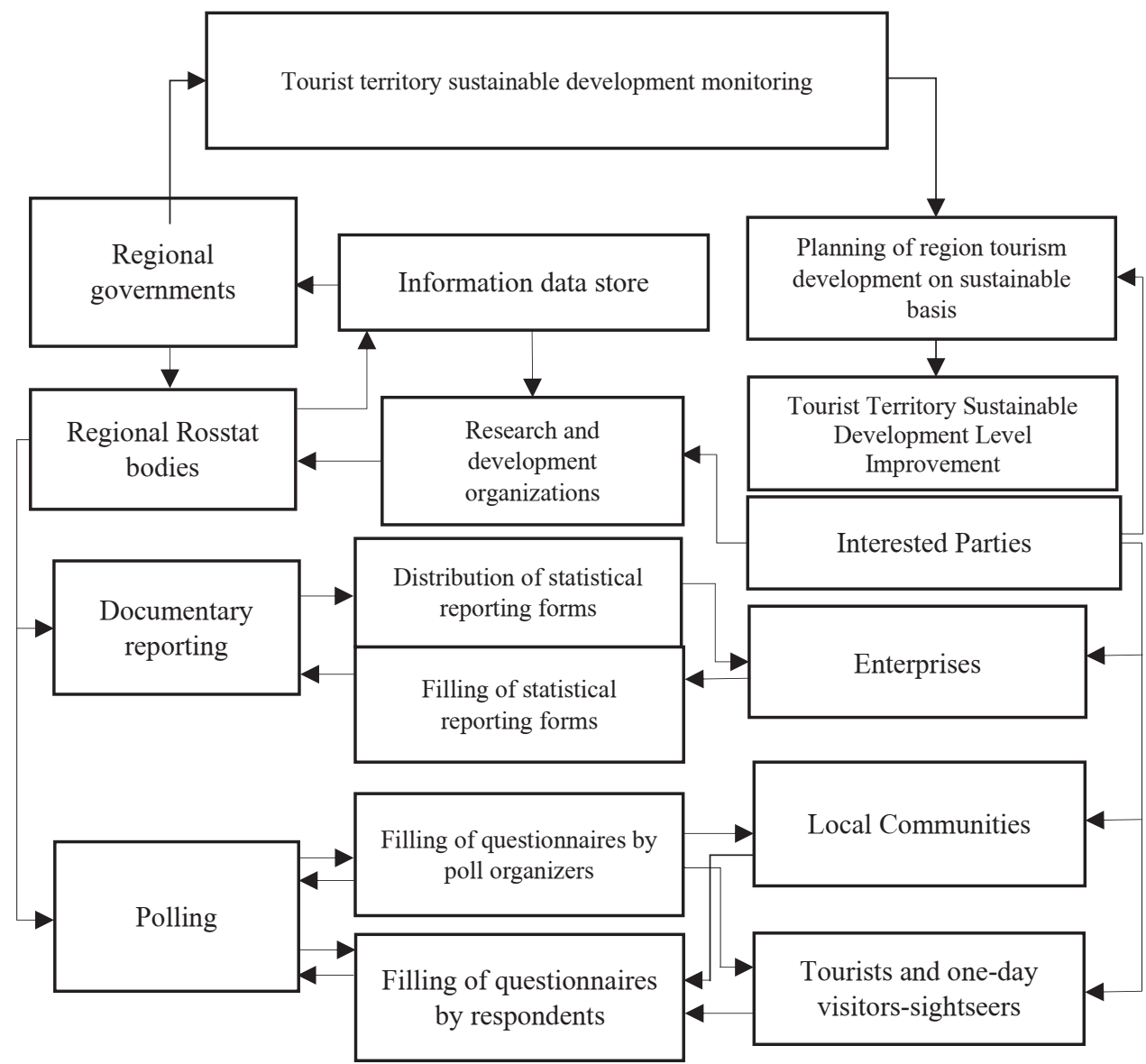

Fig. 2. Model for information data store for tourist territory sustainable development monitoring (drafted by the author)

In the presented model regional governments initiate the request to territorial bodies of Rosstat on inclusion to the statistical registration the list of indices determined upon agreement with research and development organizations as the required indices for tourist territory sustainable development monitoring.

Whereas the tourism development spans interests of great circle of interested parties, such parties shall be involved in the planning process. As enterprises are interested in the tourist flow increase and consequently the growth of tourist product turnover. Local citizens are interested in the growth of their personal disposable income and living environment quality improvement expressed in the development of social and engineering infrastructure, transportation network, etc. Moreover, local citizens are interested in favourable living environment.

The core request of tourist flow members is the obtaining high-quality tourist product and positive recreation experience in the place of destination, provided that the environmental conditions are also important for the selection of recreation place. Regional governments are interested in the taxable base expansion and growth of revenue side of consolidated budget.

Upon the available interest of statistical measurement members, the main criterion of tourism sustainable development on regional level can be considered as serving the interests of all interested groups and the monitoring of tourist territory sustainable development is meant to the tool for balance of interests' achievement. 


\section{Conclusions}

Within the conducted study authors have obtained the number of scientific and practical results characterizing key direction of tourist territory monitoring system development.

1. The prerequisite for the management of tourist territory sustainable development on the regional level is the availability of information data store comprising parameters for development of tourism, linked and procuring industries; key parameters of tourist territories' social sphere and environment status. The obtaining of required information data store is the key objective of tourist territory sustainable development monitoring, however, such monitoring in our currently is obstructed by the imperfection of domestic system of tourism statistical measurement.

2. One of key registration and statistical challenges is the determination of tourist flow. The overcoming of such challenge within the official Russian statistical measurement system does not seem possible, as such methodology is initially oriented to obtaining the information on tourist arrivals by collective accommodation facilities' load, while the informal tourist flow remains unregistered. In order to calculate the total tourist flow, several alternative methods are used, such as the calculation by number of passenger arrivals, by total territory consumption, and also mobile operators' data about mobile user (roamer) movement. The last method appears to be the most effective and is included to the federal draft action plan focused on the amendment of methods for assessment of tourist flow and tourist industry revenues.

3. Another registration and statistical challenge is the determination of indices required for measurement of economic, social and environmental territory development parameters under the tourist flow influence. In order to solve this issue, it is required to trace the chain of processes proceeding within territories under the tourist flow influence. The content of such processes determines the set of parameters using which the tourist territory sustainable development monitoring on the regional level shall be carried out. Thus, the employment creation indicated the necessity to include into the monitoring such index as the number of enterprise employees and the number of unemployed local citizens. The growth of tourist industry enterprises' revenues specifies the necessity to adopt the index "revenues from services provided by collective accommodation facilities". The increase of load on attractions and natural ecosystems actualizes the use of environmental indices such as "share of tourist territory land plots affected by negative tourist flow effects", "expenses on environment protection and restoration", etc.

4. Some indices offered by the author for inclusion to the tourist territory sustainable development monitoring is not adopted by the current Russian tourism statistical measurement system. In order to find solutions of this issue, the author has developed the model for monitoring of tourist territory sustainable development data store formation based on cooperation of regional governments, research and development organizations and interested parties. The suggested model shows that between statistical measurement members is possible to establish several forms of cooperation, such as information exchange, participation in polls, provision of statistical reporting, involvement in planning process, etc. The main advantage of this model is the possibility to form the information data store simultaneously for several information channels enabling to conduct complex statistical measurements and obtain more trustworthy result by all indices required for sustainable development monitoring.

\section{Acknowledgements}

This paper is executed under the grant of the Russian Foundation for Basic Research No. 19010-00194 A 


\section{References}

1. Miller, Graham, Twining-Ward, Louise, Tourism and Hospitality Research, 7 (2006)

2. Agenda 21, https://sustainabledevelopment.un.org/outcomedocuments/agenda21 (1992)

3. The Order of Federal Tourism Agency dd. 18.07.2007 No. 69 "On Approval the Procedure for Determining of Internal Tourist Flow in the Russian Federation and On the Tourism Contribution to the Economy of constituent territories of the Russian Federation", http://www.consultant.ru

4. D.V. Maksimov, A.I. Estafiev, Methods for Low-Cost Assessment of Tourist Flow Value on the Regional and Local Level: Research Monograph, (2012)

5. V.Ya. Gelman, Tourism Statistics: Textbook for Students of Higher Education Institutions (2010)

6. International Recommendations for Tourism Statistics (2008), https://unstats.un.org/

7. The Federal Law dd. 24.11.1996 No. 132-FZ «On the Fundamental Principles of Tourist Activities in the Russian Federation» (as amended effective of 01.07.2019), 49, 5491

8. A. Novoselov, I. Potravnii, I. Novoselova, \& V. Gassiy, Journal Of Environmental Management And Tourism, 7(3), 407 (2016)

9. E.V. Atamas, D.A. Kotelnikov, Modern economics: problems and solutions, 10 (82), 104 (2016)

10. International Working Group on Indicators of Sustainable Tourism (1993), https://www.iisd.org/

11. Indicators of Sustainable Development for Tourism Destinations: A Guidebook (2004), http://www.adriaticgreenet.org/ 